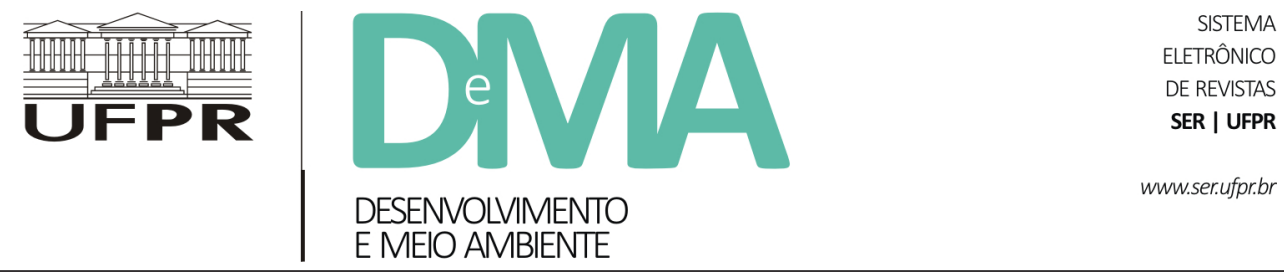

\title{
Técnica e ética ambiental: um debate entre Jonas e Larrère e Larrère
}

\section{Technique and environmental ethic: a debate between Jonas, and Larrère and Larrère}

\author{
Antônio Carlos dos SANTOS ${ }^{1 *}$, Karoline Ketilin Moura SOUZA ${ }^{1}$ \\ ${ }^{1}$ Programa Regional de Pós-Graduação em Desenvolvimento e Meio Ambiente, Universidade Federal de Sergipe (UFS), São Cristóvão, SE, Brasil. \\ *E-mail para contato: acsantos12@uol.com.br
}

Artigo recebido em 10 de fevereiro de 2017, versão final aceita em 18 de março de 2018.

\begin{abstract}
RESUMO: $\quad$ Este texto tem por objetivo analisar as implicações do poder da técnica sobre a natureza e os princípios éticos que devem visar à superação desses problemas no mundo contemporâneo, com base em três autores centrais: Hans Jonas e Catherine e Raphäel Larrère. A problemática central do texto é a de que os três autores estão de acordo quanto ao fato de que a promessa da tecnologia moderna converteu-se em ameaça para a humanidade e de que os pressupostos da ética tradicional já não se mostram suficientemente adequados para contornar essa situação. No entanto, eles entram em conflito quanto à operacionalização de uma resposta mais eficaz a esse problema. Jonas propõe o princípio responsabilidade, enquanto Larrère \& Larrère sugerem o princípio de precaução. Assim, este artigo visa contribuir com o debate atual sobre a ética ambiental nas ciências ambientais, sob uma perspectiva interdisciplinar.
\end{abstract}

Palavras-chave: ética; natureza; política; técnica.

ABSTRACT: The aim of this paper is to analyze the implications of the power of technique over nature and the ethical principles that aim to overcome these problems in the contemporary world, with Hans Jonas and Catherine and Raphäel Larrère as central authors. The central issue of this text is that these three authors are in agreement about the fact that the promise of modern technology has been converted into a threat to humanity, and that the assumptions of traditional ethics are no longer sufficiently adequate to overcome this situation. However, there is conflict regarding the operationalization of a more effective response to this problem. Jonas proposes the "responsibility principle," while Larrère \& Larrère suggest the "precautionary principle." Thus, this article aims to contribute to the current debate on environmental ethics in the environmental sciences, from an interdisciplinary perspective.

Keywords: ethics; nature; politics; technique. 


\section{Introdução}

O aumento do poder e da confiança depositada na técnica tem causado enorme temor à sobrevivência da humanidade, em razão de seu uso desordenado. A fim de evitar, ou ao menos retardar, os efeitos negativos desse empreendimento, em meados do século passado surgiu a necessidade de uma ética para melhor utilização da técnica. Em relação à discussão sobre esse assunto, três autores se destacam: Hans Jonas, autor do livro Princípio responsabilidade: ensaio de uma ética para a civilização tecnológica, e o casal Catherine e Raphäel Larrère, autores do livro Do bom uso da natureza: para uma filosofia do meio ambiente. Assim, o objetivo deste texto é analisar as implicações do poder da técnica sobre a natureza e os princípios éticos que devem visar à superação dos problemas decorrentes da técnica no mundo contemporâneo, por meio de duas diferentes interpretações. A problemática central do texto é a de que Hans Jonas e Catherine e Raphäel Larrère estão de acordo quanto ao fato de que a promessa da tecnologia moderna converteu-se em ameaça para a humanidade e de que os pressupostos da ética tradicional já não se mostram suficientemente adequados para contornar essa situação. No entanto, os autores entram em conflito quanto à operacionalização de uma resposta mais eficaz a esse problema. Jonas propõe o princípio responsabilidade, enquanto Larrère \& Larrère sugerem o princípio de precaução. Este artigo visa contribuir com o debate atual sobre a ética ambiental nas ciências ambientais, sob uma perspectiva interdisciplinar.

Este artigo é composto de três partes, além da introdução e da conclusão. A primeira tem início com os argumentos de Jonas (2006) sobre as impli- cações da técnica e a ameaça à sobrevivência das gerações futuras. Jonas apresenta um entendimento sobre as consequências do atual e incomensurável poder da técnica, cuja dimensão jamais tinha sido alcançada, o que justifica a necessidade de uma nova ética para a utilização da técnica. $\mathrm{O}$ autor propõe, então, a aplicação do princípio responsabilidade e suas ponderações têm como base o diagnóstico inicial da crise e a apresentação de uma solução para os problemas decorrentes dela. A segunda parte é dedicada ao pensamento de Larrère \& Larrère (2001), que criticam duramente o pensamento de Jonas, principalmente em relação a sua dimensão prática, que é pouco analisada pelos estudiosos de Jonas. A terceira parte é dedicada à proposta de Larrère \& Larrère, que apresentam seus pressupostos sobre as implicações da ética perante a técnica e as consequências socioambientais de seu uso, com base no princípio de precaução. Os autores desenvolvem suas ideias concordando em alguns aspectos sobre o poder da técnica, porém, no ápice de suas discussões, vão de encontro às medidas propostas por Jonas, principalmente no que diz respeito à heurística do medo como estratégia para a proteção do ambiente físico e o controle social.

Embora os três autores discordem quanto ao tipo de ética que possa combater os problemas gerados pela técnica, eles concordam que a ética ambiental, que se constituiu a partir da segunda metade do século passado, tem se solidificado cada vez mais como uma reflexão filosófica, na qual as questões clássicas da filosofia estão associadas aos problemas contemporâneos voltados para a natureza. É em torno dessa questão que este texto pretende colaborar com o debate atual. 


\section{As implicações políticas do princípio responsabilidade de Jonas}

No momento em que a promessa da tecnologia moderna converteu-se em ameaça, Jonas (2006) desenvolveu seu pensamento para demonstrar a necessidade da elaboração de uma nova ética e apresentou suas justificativas para afirmar que a ética tradicional já não se mostra suficientemente adequada para orientar a situação e garantir a existência da humanidade no futuro. Segundo Jonas (2006), a ética tradicional não consegue contemplar as novas situações e perspectivas, visto que não considera o comportamento cumulativo, nem a condição global da vida humana e tampouco as condições de existência em um futuro distante. Essa ética envolve apenas a natureza dos seres humanos, subjugando o aspecto extra-humano.

De acordo com o filósofo, a ética tradicional compartilha os seguintes pressupostos: 1) a condição humana, conferida pela natureza do homem e pela natureza das coisas, encontra-se fixada, de uma vez por todas, em seus traços fundamentais; 2) com base nesses fundamentos, pode-se determinar sem dificuldade e de forma clara aquilo que é bom para o homem; 3) o alcance da ação humana e, portanto, da responsabilidade humana, é definida de maneira rigorosa (Jonas, 2006, p. 29). Ainda segundo o autor (2006), para essa ética, a natureza não é objeto de responsabilidade humana, por isso, diante dela, são "[...] úteis a inteligência e a inventividade, não a ética" (Jonas, 2006, p. 34). Nesse contexto, a técnica é compreendida apenas como um atributo determinado pela necessidade; ela é considerada antropocêntrica e, por isso, o homem não é objeto da técnica. Não há necessidade de um planejamento a longo prazo, pois os pontos positivos e negativos são evidenciados no decorrer da ação, ou seja, as consequências ficam a critério do acaso. Além disso, a perspectiva de futuro limita-se à extensão previsível do tempo de vida do indivíduo. Assim, a ação e as suas consequências são evidenciadas em um momento presente comum.

Com base nessas características, as considerações sobre os efeitos das ações como boas ou más são inteiramente decididas tendo como base o curto prazo. Jonas aponta a invalidade de uma "ética tradicional", do próximo ou do "curto prazo", pois esta implica o fato de que "Ninguém é julgado responsável pelos efeitos involuntários posteriores de um ato bem-intencionado, bem-refletido e bem-executado" (Jonas, 2006, p. 37). Além disso, devido à extensão do poder e do fazer coletivo, "ator, ação e efeito não são mais os mesmos da esfera próxima" (Jonas, 2006, p. 39).

Além desses aspectos, o autor apresenta outra característica que é insuficiente na ética tradicional: o caráter cumulativo dos efeitos da técnica. Isso significa dizer que as situações têm se tornado cada vez mais difíceis de serem revertidas, ou, pelo menos, as condições para o restabelecimento das situações atuais já não são as mesmas que as anteriores. Jonas não questiona a validade das éticas tradicionais, mas sim a insuficiência delas, considerando-se as novas dimensões e projeções do agir humano. O filósofo argumenta que o conhecimento e sua aplicabilidade técnica inicialmente "neutralizaram" a natureza, deteriorando seu valor intrínseco a favor de um valor científico e comercial. O autor pensa, então, sobre a nova condição da ciência, apresentada como um conhecimento voltado exclusivamente para o desenvolvimento da técnica, tornando-se perigosa 
devido ao poder para controlar a natureza e orientar as decisões humanas.

Baseando-se em tais características, o filósofo alemão considera que essa ética não se mostra suficiente para contemplar as relações humanas na era tecnológica, principalmente porque o papel e a responsabilidade sobre o agir humano foram modificados. Nessa perspectiva, Jonas (1999) afirma que a ética tem algo a dizer sobre os assuntos da técnica, ou melhor, que a técnica deve subordinar-se às considerações éticas.

Ao analisar o modo como a técnica influencia a natureza do agir humano, Jonas (2006) manifesta-se a favor de uma ética que aponte os valores e os objetivos a serem atingidos, utilizando os meios (a técnica) como aquilo que realmente são, para que não sejam transformados em fins em si mesmos. Visto que, para o autor, a ameaça à vida humana é decorrente do "excesso do nosso poder de fazer, de prever [...] de conceder valor e julgar" (Jonas, 2006, p. 64), torna-se necessário ordenar as ações humanas e regular seu poder de ação diante do "agir-coletivo-cumulativo-tecnológico".

Nesse sentido, o primeiro dever da nova ética a que o autor se refere é visualizar os efeitos de longo prazo, entendendo que aquilo que deve ser temido ainda não foi experimentado. O segundo dever é a mobilização de um sentimento adequado para representar essa ética, que, segundo Jonas, seria o medo diante da situação temida; caso contrário, a possibilidade seria deixar-se afetar pela salvação ou pela desgraça das gerações vindouras. Para adoção de uma postura a favor dessa nova ética, considera-se a impossibilidade de exigir um saber que ainda não pode ser apresentado com rigor crítico-científico, de forma antecipada. Por isso, Jonas se baseia em possibilidades e em projeções de futuro como con- teúdo, e não como certeza, visto que a velocidade no avanço dos conhecimentos e seu desenvolvimento prático têm suprimido o tempo que seria necessário às eventuais correções, tornando-as cada vez mais limitadas. Daí a necessidade de vigiar os primeiros passos, cuidando para que "a herança de uma evolução anterior seja preservada" (Jonas, 2006, p. 79).

Em Jonas (2006), a prudência representa o cerne do agir moral, devendo-se considerar como certo aquilo que é duvidoso. Ou seja, se determinada ação implica consequências que não podem ser estabelecidas previamente ou que vão ocasionar risco para a humanidade futura, é certo preferir sua interrupção. O autor apresenta, desse modo, subsídios para o estabelecimento de novos princípios para o agir humano não só em relação à natureza física, mas também em relação à natureza humana.

Com o objetivo de proporcionar mudanças na concepção de que o homem deposita total confiança no aparato tecnológico e na velocidade das descobertas para efetivar seus objetivos, Jonas (2006) defende a "ética da responsabilidade" como bandeira de sua proposta, a qual deve orientar a conduta das ações humanas. Para garantir que não se torne apenas uma norma, o autor discorre sobre a utilização da política como instrumento voltado para a prática e as orientações implícitas nessa nova ética.

Considerando as ações do homem público, caracterizadas pela praticidade e pela imediaticidade, Jonas (2006) propõe a expansão dos limites de sua responsabilidade, estabelecendo o conceito de responsabilidade total, que compreende o resultado de uma ação no contexto atual e na posterioridade, determinando previamente qual resultado se deseja alcançar e a que custo. De acordo com o autor, com a responsabilidade total, ousa-se renunciar ao desenvolvimento de ações mal planejadas, ou 
desaconselháveis, por conta do desconhecimento sobre a totalidade de seus efeitos.

Nesse sentido, a responsabilidade política deve considerar as características do novo contexto em que se processam as ações e seus efeitos, tendo em vista que "o dinamismo é a marca da modernidade; ele não é um acidente, mas a propriedade imanente desta época e, até nova ordem, o nosso destino. Isso quer dizer que temos de contar com o novo, embora não possamos calculá-lo" (Jonas, 2006, p. 203). Mesmo preocupando-se com a necessidade da existência humana tanto no presente quanto no futuro, não é a responsabilidade que vai determinar o suprimento de tais necessidades, ela emerge na tentativa de possibilitar tal fato. A responsabilidade pretende evitar a emergência de efeitos pelos quais o responsável não poderá responder no futuro, seja por falta de informação ou de tempo.

Levando em consideração tal característica, de acordo com Jonas (2006), para a efetivação do princípio responsabilidade, a prevenção é uma postura muito mais eficaz que a sedução de uma promessa incerta. Mesmo o desconhecido, ou aquilo em que não se deve apostar, pode tornar-se objeto de uma política de prevenção. Assim, diante de tal desconhecimento, Jonas opta pelo cenário do pior, pois a profecia do mal é feita para evitar que ele se realize.

Baseando-se na visão que projeta um cenário negativo para conseguir garantir a participação de todos na efetivação da proposta de responsabilidade pelas gerações futuras, Jonas (2006) desenvolveu suas medidas práticas, aproximando-se da ideia de que, quanto menos comunicação e discussão sobre os temas, mais eficientes, rápidas e poderosas podem ser as decisões para solucionar esses mesmos problemas. A sociedade, então, confiaria plenamente suas decisões ao homem público, mesmo que ele imprima o medo por meio da força. Com base nesse pensamento, são apresentadas a seguir as medidas políticas de Jonas.

Segundo Jonas (2006), não se deve permitir que haja um aumento do bem-estar mundial. Para garantir a estagnação do crescimento econômico e da capacidade produtiva, o filósofo defende a postura de advertência em relação a um mal maior por vir, acreditando no medo altruísta ao invés da esperança. Prevendo a firme oposição - e mesmo reação - a essa ideia, Jonas (2006, p. 294) afirma: “[...] eu acredito que a solução está nesse caminho, se possível de forma voluntária; se necessário, forçada". Para garantir o princípio responsabilidade, o governante, para Jonas, não pode medir esforços, podendo recorrer à força bruta, a fim de garantir uma espécie de redenção futura. Diante dessa análise, o autor apresenta o paradoxo da situação atual: “[...] precisamos recuperar esse respeito a partir do medo, e recuperar a visão positiva do que foi e do que é o homem a partir da representação negativa, recuando de horror diante do que ele poderia tornar-se, ao encararmos fixamente essa possibilidade no futuro imaginado" (Jonas, 2006, p. 353).

Para o autor, somente o respeito em decorrência do medo protegeria o homem da destruição do presente em nome do futuro. Entretanto, tal medo não se refere à incerteza. De acordo com o filósofo, "O medo que faz parte da responsabilidade não é aquele que nos aconselha a não agir, mas aquele que nos convida a agir. Trata-se de um medo que tem a ver com o objeto da responsabilidade" (Jonas, 2006, p. 351). Ou seja, o temor é favorável à preservação do objeto e as ações devem estar voltadas para esse fim.

Em uma tentativa de justificar o rumo paternalista e autoritário que vigora na aplicação 
prática de sua argumentação, Jonas (2006) afirma que, independentemente do modo como as atitudes sejam manifestadas, o que importa é possibilitar a continuidade da vida humana e sua essência natural, bem como a da natureza física, da melhor forma possível. O filósofo entende que os males oriundos da degradação do patrimônio físico natural estendem-se proporcionalmente aos seus herdeiros. Impedir que esse quadro seja efetivado significa assumir a responsabilidade pelo futuro do homem.

Além disso, é possível afirmar que o filósofo compartilha do pensamento antropocêntrico, quando afirma que a natureza conserva sua dignidade e contrapõe-se ao poder humano. Para Jonas (2006, p. 229), "Quando a luta pela existência frequentemente impõe a escolha entre o homem e a natureza, o homem, de fato, vem em primeiro lugar". Por isso, proteger o futuro da humanidade é o primeiro dever, o qual inclui o futuro da natureza unicamente por ser a condição para efetivá-lo.

Enfim, as reflexões de Jonas sobre o poder da técnica não implicam, necessariamente, uma preocupação com a natureza, entendida como o ambiente físico, mas sim uma preocupação com a manutenção da natureza para a sobrevivência do homem. Entende-se que sua inquietação está centrada na sobrevivência da humanidade, ameaçada pela técnica, e na necessidade de uma ética para a utilização desta. Jonas não discorda do fato de que a ciência é importante para o desenvolvimento do homem; seu problema não está na ciência, mas na maneira como esta pode ser manipulada, a fim de possibilitar sua aplicação, ou seja, no perigo proveniente do poder que a técnica exerce sobre o homem e a natureza.

\section{As críticas de Larrère e Larrère às estratégias do princípio responsabilidade de Jonas}

Larrère \& Larrère (2001) caracterizam a importância da obra de Jonas em seu contexto histórico e apresentam críticas às soluções preconizadas pelo filósofo alemão e, principalmente, ao caráter autoritário da proposta de Jonas. Além disso, os autores mostram-se contrários aos procedimentos e às justificativas utilizadas pelo filósofo para informar suas medidas, as quais visavam estabelecer uma heurística do temor.

De acordo com Larrère \& Larrère (2001), durante os primeiros anos da publicação de Jonas, não havia consenso a respeito da crise ambiental, razão pela qual seu pensamento não recebeu a atenção devida. Porém, a globalização transformou a recepção de sua obra e trouxe a possibilidade de uma crítica mais apurada. Conforme afirmam os autores, "[...] quando nosso poder técnico crescente revela ao mesmo tempo a fragilidade das condições naturais de que ele depende para continuar e as ameaças que elas fazem pesar sobre nós, começa-se a ouvir Jonas" (Larrère \& Larrère, 2001, p. 266).

Em sua obra, Jonas tenta estender à natureza uma preocupação que ficou circunscrita às comunidades humanas, pois, até certo ponto, as ações antrópicas perturbavam a natureza apenas superficialmente. Porém, quando o poder e a capacidade técnica intensificaram essa relação, tornando-a perigosa para o homem, surgiu a necessidade de uma nova dimensão de responsabilidade. Isso significa dizer que, para Larrère \& Larrère (2001), Jonas analisa a questão da técnica com lucidez, mas a proposta política feita por ele para a solução 
do problema não coincide com sua postura ética: a heurística do medo de Jonas antecipa a catástrofe, retirando toda a capacidade humana de pensar ações livres que possam contornar o problema de outra maneira, levando em conta o debate público e o conhecimento científico esclarecido.

Larrère \& Larrère (2001) afirmam que a ambiguidade presente na obra de Jonas se deve ao fato de que, mesmo denunciando a utopia técnica, o filósofo continua preso à ilusão do poder total, acreditando na capacidade técnica para controlar todas as ações humanas, por meio de uma previsibilidade programada. Assim, Jonas, ao procurar "substituir a ciência pela ética, mantém sua separação" (Larrère \& Larrère, 2001, p. 267), na medida em que exclui das decisões o debate público, por meio da "aterrorização" sobre uma catástrofe natural da qual todos deveriam proteger-se para evitar o pior. Ora, essa ideia não só é incômoda, pois se trata de um princípio político, mas também é perversa, pois traz um elemento religioso intrínseco, que vai na contracorrente das éticas laicas modernas. A ética da responsabilidade de Jonas é como uma ética religiosa, de abstinência e de sacrifício, e não como uma ética da moderação. Por isso, afirmam Larrère \& Larrère (2001, p. 274), Jonas faz “[...] da mesma forma que se ameaçam os crentes com os horrores do inferno, já que não é possível incliná-los diretamente para o bem".

No entanto, por que Jonas faz tão bem a análise da técnica e, ao mesmo tempo, é tão obtuso do ponto de vista político? Para Larrère \& Larrère (2001), Jonas teria dificuldade de estabelecer essa ética no campo político porque não se presta ao debate democrático. "Jonas não acredita na capacidade das democracias para se libertarem dos seus interesses presentes, para preverem a ameaça e imporem a si mesmos a obrigação provinda do futuro" (Larrère \& Larrère, 2001, p. 275). O filósofo alemão ignora a racionalidade argumentativa e tem enorme dificuldade de entender a democracia como valor do mundo contemporâneo. Portanto, o posicionamento autoritário de Jonas não permite a compreensão da política em pleno século XX.

É importante destacar que Larrère \& Larrère (2001) não são os únicos a fazer essa crítica a Jonas. Semde (2015), ao analisar a ética e a política em Jonas, também faz coro às críticas ao alemão sobre a mesma questão, fundamentando-se em dois argumentos: a) Jonas pensava que a falta de dados científicos absolutos sobre as consequências danosas à natureza deixava margem a dúvidas, razão pela qual não se pode fundar uma ética em um pensamento duvidoso; 2) Jonas defendia uma mudança política global, na qual os cidadãos deveriam se sacrificar em nome do bem maior, o comum, especialmente tendo em vista as gerações futuras, e, com isso, pressupunha cidadãos virtuosos e abdicados. Em tom sarcástico, Semde (2015, p. 160) pergunta: "O homem de Estado preocupado em conservar seu poder pode optar em sacrificar as necessidades presentes e às vezes urgentes dos cidadãos atuais sobre o qual ele deve contar para se manter no poder em nome de um cidadão apenas virtual?". Ou seja, a dificuldade maior do pensamento de Jonas é justamente fazer a ponte entre seu pensamento ético e as atividades políticas que exigem questões práticas, urgentes e necessárias.

\section{A proposta de Larrère e Larrère ao problema da técnica}

Com base na crítica ao pensamento de Jonas e ao seu princípio ético da responsabilidade, Larrère 
\&Larrère apresentam como alternativa o princípio de precaução. Esse conceito é problemático porque não se tem consenso sobre sua definição, razão pela qual Guillaume (2012, p. 491) afirma que há uma verdadeira "querela do "princípio de precaução". De qualquer modo, esse conceito é uma norma prática, que toma a forma jurídico-política nas sociedades democráticas como resposta aos eventuais riscos ambientais, sejam estes relacionados a comunidades específicas ou a toda a humanidade. Grosso modo, há duas versões explicativas. Na primeira (versão forte), a ideia de precaução é um critério absoluto, instituindo-se como uma regra de abstenção, que tem como consequência a paralisação das atividades existentes e o desencorajamento à inovação. Na segunda (versão fraca), é um critério parcial, que abre espaço ao debate público, à deliberação e aos processos de justificação em razão de riscos à natureza e ao homem. Independentemente da versão, em ambas há o afastamento do cenário único, caracterizado pela profecia do medo e da desgraça de Jonas.

Segundo Larrère \& Larrère (2001), o medo não convence e, por isso, nada melhor que combatê-lo por meio da negociação, da conversa, do convencimento público da palavra. Além do mais, exigir um respeito à natureza baseado no temor é ineficaz. Assim, é preciso "[...] estabelecer pelo debate público as regras do que é justo para que a sociedade imponha a todos os membros" (Larrère \& Larrère, 2001, p. 279). O objetivo não é encontrar uma solução perfeita, de maneira técnica e institucionalizada, mas sim organizar os processos de decisão conforme o tempo disponível, prezando, acima de tudo, pela informação e pela participação da opinião pública, ou seja, pela aprendizagem coletiva.
Baseando-se no modelo do debate público para propor o princípio de precaução, Larrère \& Larrère defendem que a razão deve sobrepor-se ao medo. Esse princípio apresenta-se muito mais adequado ao espaço político da democracia e evita aplicações absolutistas ao andamento das atividades sociais, por meio das articulações entre prudência, política e ciência. Tal posicionamento, além de prevenir riscos, minimiza a insegurança oriunda da falta de informação por parte da população. Além disso, é em meio aos conflitos e às pressões sociais que surgem as melhores formas de se extrair soluções positivas e autênticas.

O princípio de precaução não se encerra na pura e simples interdição das ações e na paralisação das atividades. Por meio da inversão do ônus da prova, esse princípio introduz mecanismos que permitem ultrapassar tal processo, devido ao estímulo ao desenvolvimento dos conhecimentos que envolvem o risco. O objetivo não é imputar a culpa, a fim de paralisar as atividades econômicas e técnicas, mas sim impor a obrigação de saber sobre a dinâmica das consequências indesejados sobre a população a longo prazo.

É nesse sentido que o princípio de precaução requer três importantes aspectos: 1) o engajamento de toda a sociedade em relação ao conhecimento da natureza que envolve determinada população; 2) os riscos eventuais que possam atingir esta mesma população; 3) as ações necessárias que possam contornar os problemas potenciais, razão pela qual esse princípio tem sentido político e ético. Político porque exige que as instituições se preparem para os riscos causados pela própria técnica, por meio de políticas públicas; ético porque deve mobilizar todo cidadão consciente de seu papel na sociedade. Como afirma Guéry (2012, p. 611), "a precaução 
é uma incitação ao melhor cenário, a um futuro melhor, cultivando uma imaginação preventiva, complementar à inovação".

De acordo com Larrère \& Larrère (2001), na medida em que o agir técnico deliberadamente possibilita a transformação do conhecimento em ação, há um crescimento do poder e uma eventual busca de solução para os problemas das populações atingidas pelos mesmos riscos que a técnica criou. Já a natureza, onde o poder é empregado, é vista como algo desprovido de valor e que, sem a presença humana, traz sérios danos. A igualdade e a universalização no tratamento dispensado à preservação da natureza consistem em apagar as diferenças de posicionamento da humanidade entre as gerações presentes e futuras. $\mathrm{O}$ homem deve ser visto como uma parte pertencente à natureza e que influencia o modo de vida dela. Portanto, a limitação da ação técnica tende a reconhecer a ação do homem na natureza - e sobre a natureza -, estabelecendo uma relação de pertencimento. A relação de copertença, baseada em tais princípios, pretende mostrar que o conhecimento transforma o mundo por meio da ação, mas que este não é apenas um mundo que pode ser moldado ou manipulado de maneira imparcial. Este mundo, ou seja, a natureza, é antes de tudo um mundo valorizado, e não apenas algo estático percebido de forma neutra. Isso significa dizer que a ética do princípio de precaução é, no fundo, ecocentrada, ou seja, fundada na relação de pertença, que não implica apenas uma representação científica do mundo, mas sim uma maneira de nele situar o homem e suas relações sociais, com base na valorização da natureza. Por isso, não se restringe a modificações normativas, mas favorece, principalmente, mudanças comportamentais.
Não é verdade que os problemas nascidos da técnica devem ser resolvidos por meio de soluções técnicas, porque a tecnologia contemporânea é a ciência convertida em poder. A ciência apenas informa a técnica; ela não lhe impõe normas, razão pela qual a técnica torna-se um processo ilimitado. Para Larrère \& Larrère (2001), as proposições para a limitação da ação técnica não consideram o agir humano de maneira isolada, mas sim situado na natureza. Isso implica decisões que, para serem realizadas com base no princípio de precaução, precisam do conhecimento da ação do homem na natureza, e não apenas sobre a natureza. Portanto, a relação que Larrère \& Larrère estabelecem é a de "copertencimento": o sentimento de que homem e natureza estão próximos e são mutuamente afetados.

Nesse sentido, a ética ambiental pretende pensar a natureza como portadora de uma dignidade moral, ou seja, de um valor intrínseco, mas também entende que essa mesma natureza não está apartada do homem e, por isso, tem preocupação política. Por essa razão, para Larrère \& Larrère (2001), os princípios do ecocentrismo estão fundados no pensamento daquele que é considerado o fundador da ética ambiental americana: Aldo Leopold. Uma "coisa é justa quando ela tende a preservar a integridade, a estabilidade e a beleza da comunidade biótica. Ela é injusta quando tende ao inverso" (Leopold, 1995, p. 283). Isso implica dizer que o homem está imerso na natureza e dela faz parte todo ser existente, e todos os elementos dessa grande comunidade têm importância para o próprio equilíbrio da natureza (Callicott, 1989). 


\section{Considerações finais}

As contestações sobre a viabilidade e a inocuidade do progresso, o qual está fortemente baseado no poder da técnica e na garantia da ciência sobre a segurança em relação aos efeitos decorrentes da utilização desse poder, indicam que Jonas (2006) e Larrère \& Larrère (2001) situam-se no terreno da ética ambiental. Suas análises exercem grande influência no mundo contemporâneo e implicam um posicionamento político que tem como finalidade reorientar a maneira de pensar e almejar o progresso $\mathrm{e}$, consequentemente, o posicionamento humano diante da necessidade de sobrevivência do homem na Terra. A grande pergunta que deve ser feita é: Como superar as dificuldades da técnica, visando preservar de suas catástrofes tanto as sociedades presentes quanto as futuras? Conforme vimos, duas possibilidades foram apresentadas: a de Jonas e a de Larrère e Larrère.

Jonas (2006) defende o princípio responsabilidade. Para esse filósofo, a dificuldade maior não é o fato de que o emprego da técnica tenha modificado e degradado a natureza física, mas sim o fato de a técnica estar manipulando a natureza humana. Assim, o homem tem perdido o controle sobre a técnica e já não exerce a capacidade de perceber como ela tem determinado as formas de organizações sociais e, principalmente, acarretado perigo à existência da humanidade. Por isso, Jonas argumenta a necessidade de expansão dos limites da responsabilidade como cerne do agir moral. Nesse sentido, a responsabilidade pelo emprego da técnica passa a incluir as consequências posteriores de sua utilização, em todos os níveis. Entretanto, as orientações para aplicação desses princípios são compreendidas por meio da necessidade de controle total das decisões por parte do dirigente político.

Apesar de reconhecer a importância das decisões tomadas em momentos de crise, Jonas as caracteriza como um dever imposto ao homem, surgido de uma ameaça maior, razão pela qual tais decisões são permeadas por um aspecto impositivo. Essa solução política é controversa. Para esse filósofo, o poder sobre a decisão e a necessidade de aplicação das ações voltadas para a preservação das futuras gerações parte impreterivelmente do homem público: é ele quem pode decidir sobre o melhor para a sociedade. As medidas de Jonas são impositivas, uma vez que o autor não acredita na participação social para a resolução de questões coletivas, mas sim na eficiência de um Estado paternalista e, como dito anteriormente, autoritário. As imposições devem ser acatadas tendo em vista o temor coletivo sobre um mal maior que poderá emergir no futuro, tendo em vista a ameaça do desaparecimento da espécie humana na Terra.

Assim, Jonas constrói um cenário baseado na profecia do mal, espalhando um medo coletivo (que considera "altruísta"), tendo em vista tratar-se de um temor pela salvação da vida no presente, mas também pela vida da humanidade que está por vir. Seus objetivos são possibilitar a continuidade da existência humana e impedir a qualquer custo que os males estendam-se às gerações futuras, ainda que as decisões do homem público não sejam acatadas com o consenso da sociedade.

A proposta de Larrère \& Larrère (2001) para a mesma questão é de outra ordem: o princípio de precaução. Isso significa dizer que o sentido de preservação da natureza e a garantia da existência das gerações futuras situam-se longe da manutenção de uma perspectiva de natureza selvagem, preservada 
em seu estado primitivo, sem qualquer interferência humana. O que se considera importante preservar é a capacidade evolutiva dos processos ecológicos, pois só assim é possível proporcionar condições para a existência da humanidade no futuro. Além disso, essa proposta não compreende as ações humanas e a utilização da técnica unicamente sob o prisma de seus efeitos negativos e destrutivos para o meio ambiente. As reflexões políticas dos ecologistas expõem até que ponto os problemas do meio ambiente, ocasionados pela má utilização da técnica, têm influência nas condições de vida das populações e reforçam as desigualdades sociais.

No entender de Larrère \& Larrère (2001), a dimensão ética dos problemas ambientais, a importância da publicidade do debate público sobre essas questões, a necessidade de diversificação nas investigações científicas, a fim de tornar mais sensíveis as limitações da ciência, e a confiança no aparato tecnológico são aspectos essenciais na resolução dos problemas sociais e ambientais, de modo a se ter clareza de que o homem deve estar contemplado na natureza, e não fora dela.

Se Jonas propõe a "heurística do medo" como ápice de seu princípio responsabilidade, o que acaba por caracterizar uma ética religiosa, de abstinência e de sacrifício, Larrère \& Larrère propõem o debate público para seu princípio de precaução, no qual a participação social é estimulada e a informação é fundada na ética ecocentrada, que denota a maneira de o homem situar-se no mundo com suas relações sociais, considerando aí a própria natureza. Essas ações visam evitar as aplicações absolutistas no tratamento das questões ambientais requeridas por Jonas, conforme analisado neste estudo.

Enquanto em Jonas o meio ambiente é caracterizado como um patrimônio homogêneo e previ- sível, em Larrère \& Larrère este é compreendido como um bem comum, cuja gestão se dá mediante negociação. Neste ponto, é válido questionar qual o tipo de natureza se pretende transmitir às gerações futuras, com base na oposição de ideias dos autores. Ao tratar a questão ambiental de forma impositiva, pensando no meio ambiente como um espaço físico, Jonas reforça a dicotomia homem/natureza, na medida em que as decisões não consideram a participação da comunidade local, ou seja, do homem em seu meio ambiente. A partir do momento em que se pensa na preservação do meio ambiente por meio da negociação, o homem é tomado como um ser da natureza e na natureza, extraindo de sua convivência e de seus costumes os aspectos positivos que favorecem a preservação tanto da natureza física quanto da humana. Ao se entender que cada comunidade tem uma relação peculiar com o meio ambiente e que este não é neutro, o meio ambiente passa a ser valorizado e percebido de forma diferente. Assim, as relações não podem ser homogêneas.

Por fim, a principal contribuição de Larrère e Larrère para os propósitos deste artigo, além do debate com Jonas, está no fato de que os autores defendem as implicações do poder da técnica para além da perspectiva dos impactos na natureza física, de modo a possibilitar, então, a reflexão sobre os valores e os objetivos da sociedade, bem como sobre as consequências negativas da confiança imputada exclusivamente à técnica na resolução dos problemas ambientais. Essa reflexão culmina com a busca por uma nova ética que possibilite a utilização da técnica como aquilo que ela realmente é, ou seja, um meio, e não um fim em si mesma.

Portanto, os três autores estão de acordo quanto ao fato de que a promessa da tecnologia moderna converteu-se em ameaça e que os pressupostos da 
ética tradicional já não se mostram suficientemente adequados para orientar a situação. No entanto, entram em conflito quanto às perspectivas éticas que se impõem e às circunstâncias práticas do homem, ou seja, quanto à operacionalização desses mesmos princípios. Jonas volta-se para a dimensão político-paternalista presente em seu princípio responsabilidade, enquanto Larrère \& Larrère orientam-se na direção próxima ao republicanismo, pressupondo o exercício da alteridade, da cidadania e da participação comunitária, por meio do princípio de precaução.

Se entendermos a crise ambiental como consequência da técnica que foi posta a serviço do desenvolvimento econômico, precisamos compreender que a resposta a essa mesma crise não pode ser apenas técnica, muito menos econômica. Essa resposta passa por outros modos de valorização da natureza que, no fundo, passam por uma preocupação conosco, mesmo porque nós não estamos sós no mundo. O perigo do desaparecimento não é só de determinada espécie de animal ou de planta, mas da própria condição humana. É esse fato que nos impõe repensar nosso lugar no mundo atual e pensar nas gerações futuras, se quisermos deixar algum legado a elas.

\section{Referências}

Callicott, J. B. The conceptual Foundations of the Land Ethic, In: Defense of the Land Ethic: Essays in Environmental Philosophy. Albany (NY), State University of New York Press, 75-100, 1989.

Guillaume, B. L'esprit de la précaution. Revue de métaphysique et de morale, 76, 491-509, 2012. doi: 10.3917/ rmm.124.0491
Guéry, F. La précaution comme souci. Revue de métaphysique et de morale, 76, 611-621, 2012. doi: 10.3917/ rmm.124.0611

Larrère, C.; Larrère, R. Do bom uso da natureza: Para uma filosofia do meio ambiente. Lisboa: Instituto Piaget, 2001 (Coleção Perspectivas Ecológicas).

Leopold, A. Almanach d'un comté des sables. Paris, Aubier, 1995.

Jonas, H. Por que a técnica moderna é um objeto para ética. Tradução Oswaldo Giacoia Júnior. Natureza Humana: Revista Internacional de Filosofia e Práticas Psicoterápicas, 1(2), 407-420, 1999.

Jonas, H. O Princípio Responsabilidade. Rio de Janeiro: Contra ponto Editora, 2006.

Semde, C. Éthique et politique chez Hans Jonas: pour une philosophie politique de l'environnement. Paris: l'Harmattan, 2015. 